\title{
Pinocchio, Pinóquio - o Percurso de um BONECO DE MADEIRA NO BRASIL
}

\begin{abstract}
Maysa Ketherine Rizzotto*
RESUMO: A obra de Carlo Collodi (1826 - 1890) Pinocchio é conhecida no mundo inteiro por suas diferentes traduções e adaptações. Esse trabalho propõe uma análise, a partir do conceito de paratexto de Gérard Genette, de algumas edições brasileiras, publicadas entre 1929 e 2012. O objetivo, portanto, é pensar como essa obra foi sendo apresentada ao longo das décadas para o leitor brasileiro.

PALAVRAS-CHAVE: Pinóquio; paratexto; Carlo Collodi.
\end{abstract}

ABSTRACT: L'opera di Carlo Collodi (1826 - 1890) Pinocchio è conosciuta nel mondo intero grazie alle traduzioni e agli adattamenti. Questo lavoro propone un'analisi, partendo dal concetto di paratesto di Gérard Genette, di alcune edizioni brasiliane, pubblicate tra il 1929 e il 2012. L'obiettivo è quello di pensare a come quest'opera è stata presentata al lettore brasiliano nelle diverse epoche. PAROLE CHIAVE: Pinocchio; paratesto; Carlo Collodi.

ABSTRACT: Carlo Collodi's book Pinocchio is known worldwide for its various translations and adaptations. This paper proposes an analysis from Gérard Genette's concept of paratext of some Brazilian editions, published in Brazil between 1929 and 2012. The goal is to analyse how this work has been presented over the decades for the Brazilian reader.

KEYWORDS: Pinóquio; paratext; Carlo Collodi.

*Universidade Federal de Santa Catarina, Florianópolis (Brasil) - maysarizzotto@gmail.com

Processo n.2013/20971-0 Fundação de Amparo à Pesquisa do Estado de São Paulo (FAPESP)

DOI: http://dx.doi.org/10.11606/issn.2238-8281.v0i33p96-103 
atural de Florença, Carlo Lorenzini, ou melhor, Carlo Collodi, como assinava suas obras, entre elas a de interesse desta pesquisa, começa a escrever seus textos no mesmo período em que participava das batalhas pela unificação da Itália (1848-49). Comediante, criou histórias engraçadas e irônicas como Macchiette (1880), Occhi e nasi (1881) e Storie allegre (1887), publicadas no jornal Il Fanfulla.

Seu contato com a literatura infantil ocorre quando traduz contos de fada de Charles Perroult, Racconti delle fate, em 1875. Aproximadamente neste período, algumas mudanças estavam ocorrendo na letteratura per l'infanzia, que inicialmente tinha um escopo pedagógico e então passava a ter um caráter mais lúdico. Por esse motivo, Ferdinando Martini, jornalista e diretor do jornal para o qual Collodi criou as histórias citadas anteriormente, sugere um novo suplemento para Il Fanfulla, intitulado Giornale per i bambini. Em 1881, no primeiro número deste suplemento, dois capítulos de La storia di un burattino são publicados, marcando assim o surgimento do boneco de lenha. Em um espaço de tempo de 18 meses, são publicados 15 capítulos, com a conclusão da história marcada pela morte de Pinóquio; porém, a popularidade do personagem e a insistência do editor convencem Collodi a retomar a história, que assume o seu título definitivo: Le avventure di Pinocchio e tem o seu final refeito: o boneco de madeira se torna um menino de verdade. Em 1883, a história passa a contemplar 36 capítulos, é publicada por Felice Paggi - Libraio editore e tem suas primeiras ilustrações feitas por Enrico Mazzanti. 
Não obstante seus 134 anos, o percurso traçado por Pinóquio foi marcado pela sua capacidade de perviver atravessando culturas e línguas para as quais foi traduzido, além de adaptações para o cinema e teatro, permanecendo o mesmo, "indene às mutações do gosto, das modas, da linguagem, dos costumes, sem jamais conhecer períodos de eclipse ou de esquecimento" (Calvino, 2011, p. 347). Ítalo Calvino, em seu ensaio publicado no jornal La Repubblica em 1981 - ano do centenário de Pinóquio -, que também foi publicado ao modo de posfácio pela editora Cosac Naify em 2011, explica que:

O segredo deste livro, em que nada parece ter sido calculado, que a trama se desenvolve ponto a ponto a cada capítulo [...] está na necessidade interna de seu ritmo, de sua sintaxe de imagem e metamorfoses, que faz com que um episódio deva seguir-se a outro numa concatenação propulsora. (CALVINO, 2011, p. 348)

Vale ressaltar também que Calvino, no mesmo texto, admite ter considerado Pinóquio um "modelo de narrativa de aventuras" (CALVINO, 2011, p. 348) e o equipara a I promessi sposi, de Manzoni e alguns diálogos leopardianos.

Feito este breve panorama, se pretende analisar alguns aspectos relevantes e a partir do conceito de paratexto de Gerard Genette, este texto se deterá no conceito de título e em alguns aspectos das capas, para pensar em como a obra, mundialmente famosa, de Collodi foi apresentada para o público brasileiro.

É sabido que Pinóquio é amplamente considerado literatura para crianças, mas quais elementos paratextuais podem contribuir para tal afirmação? Em busca de respostas, além de consultar algumas traduções publicadas nos anos 1929 (tradução de Mary Baxter Lee, Livraria Liberdade), 1933 e 1962 (tradução revista por Monteiro Lobato, Companhia Editora Nacional), 1954 (tradução de Mário da Silva, Casa Editora Vecchi Ltda.), 2002 (tradução de Marina Colasanti, Companhia das Letrinhas) e 2011 (tradução de Ivo Barroso, Cosac Naify), foi consultado o acervo do jornal Folha de São Paulo na intenção de verificar outras adaptações da obra, os títulos a elas atribuídos e se essa escolha foi possivelmente direcionada a um determinado público, seja ele infantil, jovem, adulto etc., visto que, o público é o destinatário do título (Genette, 2009), que, como elemento paratextual, tem a capacidade de transmitir uma breve informação, intenção ou até mesmo uma interpretação, tornando-se assim uma força elocutória rica e imediata (Araújo, 2011). 
Neste sentido, o título resume-se em três funções principais: designação, indicação do conteúdo e sedução do público (Genette, 2009, p. 73). Já a escolha dos elementos encontrados nas capas ocorreu pelo fato de que alguns deles são mais (caso das ilustrações e do título) ou menos (caso do prefácio) recorrentes nos livros consultados.

Nos livros traduzidos, além do título, alguns dos elementos das capas são de igual relevância no que se refere à escolha de um público, tais como subtítulos, as ilustrações, indicação de coleção, autor e tradutor. Do cotejamento das capas e títulos, verificou-se que na edição de 1929, ainda pouco conhecida, a capa oferece algumas ilustrações em um fundo todo vermelho, sendo o título o nome do personagem em grafia italiana Pinocchio com o seguinte subtítulo: aventuras maravilhosas de um boneco de pau, seguido pelo nome do autor italiano. A literatura infantil no Brasil neste período também tinha um caráter pedagógico, pois devido a grandes mudanças da época havia grande expectativa na educação e a literatura infantil esteve a ela muito ligada; as primeiras obras para o público infantil eram traduções e adaptações de obras estrangeiras e no início do século XX buscava-se descrever o Brasil como um país de natureza belíssima (PEAD UFRGS, 2010).

É nesse contexto que entra edição de 1933, pois em sua capa há a ilustração de Pinóquio em uma floresta sendo alertado de algum perigo iminente por uma arara-vermelha. Esta edição, em que Pinocchio também está em grafia italiana, é, geralmente, tida como a primeira tradução feita para o português brasileiro, ${ }^{1}$ numa tradução revista por Monteiro Lobato, que foi o primeiro escritor a expor seu interesse em escrever em uma linguagem para o público infantil de forma atraente. O que salta aos olhos é o fato de seu nome estar na capa, talvez pela intenção de persuadir e cativar um público, ou melhor dizendo, seduzir, dada a notoriedade do escritor. Na capa desta edição ainda registra-se que o livro faz parte da coleção literatura infantil da Biblioteca Pedagógica Brasileira, legitimando assim, a escolha de um público.

No entanto, na reedição do livro em 1962 pela Editora Companhia Nacional, as informações paratextuais da capa limitam-se ao título em grafia italiana Pinocchio, ao nome do autor e da editora, além da ilustração de um boneco de madeira de feição inocente e ingênua.

A edição de 1954, intitulada Pinocchio, também em grafia italiana com a escolha explicada em nota, contempla apenas 18 capítulos, mesmo que na capa conste como edição completa,

1 PETERLE, Patricia, SANTURBANO, Andrea, WATAGHIN, Lucia (org.), Literatura italiana traduzida no Brasil 1900-1950, Niterói, RJ: Comunità, 2013. 
pertence à serie Obras-primas Juvenis, de formato grande e papel cartonado, com ilustrações na capa e o subtítulo: as mais famosas aventuras fantásticas, jocosas e morais que empolgaram milhões de meninos e adultos do mundo inteiro, no livro e no cinema, certificando que Pinóquio é feito para crianças, jovens e adultos.

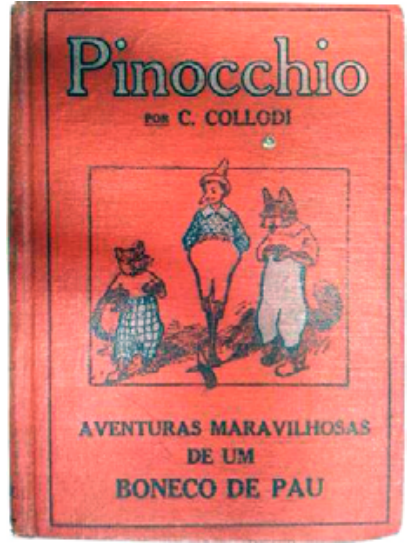

Edição de 1929

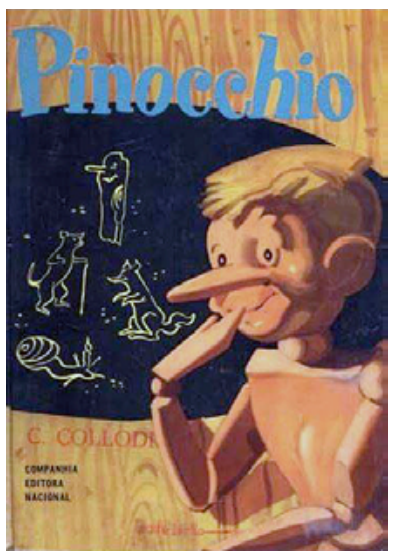

Edição de 1962

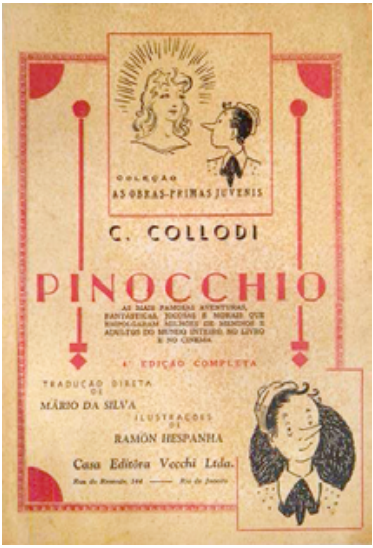

Edição de 1954

Em uma tradução mais atual, lançada pela Companhia das Letrinhas, única indicação de literatura infanto-juvenil, tem-se possivelmente o título que mais se aproxima do original, assim como ocorre na edição mais recente lançada pela editora Cosac Naify: As aventuras de Pinóquio. A primeira capa apresenta riqueza de detalhes, enquanto a segunda tem um fundo azul e traços minimalistas, porém ambas trazem a imagem do boneco de madeira. Ainda em 2011, a Cosac Naify lança uma edição especial com capa em cor marrom remetendo à madeira e a letra $\mathrm{Q}$ de Pinóquio aos anéis de crescimento de uma árvore. Esta edição da Cosac Naify é, provavelmente, destinada ao público adulto que teve contato com Pinóquio na infância, visto que o seu formato é pouco sedutor para uma criança. 


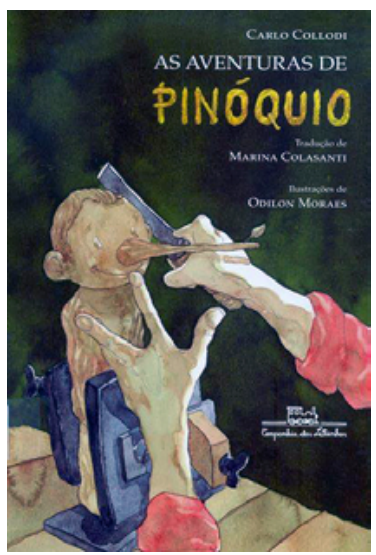

Edição da Companhia das Letrinhas

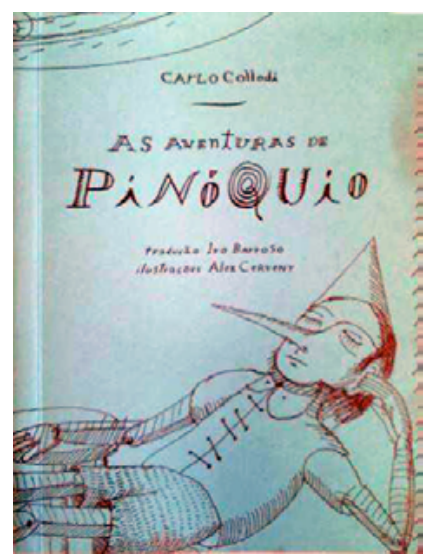

Edição da Cosac Naify

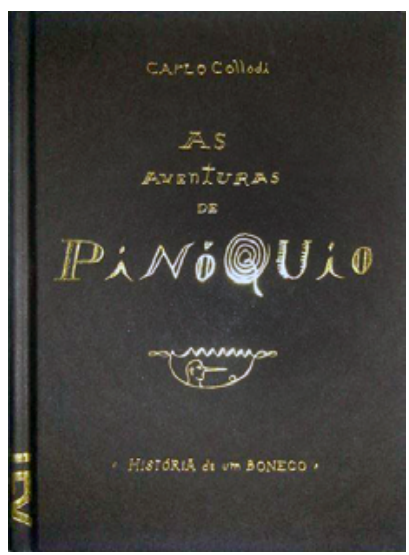

Edição especial da Cosac Naify

Após percorrer o acervo do jornal Folha de São Paulo e consultar alguns dos 990 resultados para Pinocchio em grafia italiana e mais de 1300 resultados em vernáculo, constatou-se que uma adaptação que seduziu o público infantil foi o famoso filme de Walt Disney, Pinocchio, de 1940, noticiado a partir da mesma década através de programações diárias do cinema e de críticas. A adaptação de Disney esteve sempre sendo retomada pelos cinemas até a década de 1990 através dos títulos: Pinocchio - Desenho colorido de Walt Disney, Pinocchio - super desenho de Walt Disney ou apenas Pinocchio, alcançando muitas gerações e tornando-se a versão mais popular do burattino.

Porém, a facilidade em ser adaptado para o desenho animado gerou divergências entre as histórias: no livro, que captura o ambiente de "vadiagem e de fome, de hospedarias mal frequentadas" (Calvino, 2011, p. 346), Pinóquio é egoísta, ingrato e desobediente, a casa de Gepetto não passa de um casebre quase vazio, e o grilo é morto por Pinóquio, enquanto que no filme, Pinóquio é inocente e bonzinho, a casa de Gepetto é confortável e o grilo falante é a "consciência" personificada do boneco, fazendo desta versão pura fantasia, sem que os traços essenciais fossem deixados de lado. Em 1996, com o título As aventuras de Pinocchio, o filme de Steve Barron narra a história do boneco de lenha com personagens de carne e osso de modo menos fantasioso, porém mais honesto.

Além disso, foram encontradas incontáveis adaptações para o teatro, com os títulos: $A$ 
maravilhosa fábula de Pinócchio, A verdadeira história de Pinocchio, Pinocchio; musical, espetáculo de balé e até um memorial do Pinocchio nel mondo, tendo a maioria uma indicação classificatória de faixa etária, variando de adaptações indicadas para acima de 2, 4 e até 7 anos. A obra de Collodi serviu, ainda, de inspiração para mais uma adaptação para os cinemas, intitulada As aventuras de Pinocchio 2, destinada ao público infantil, lançada em 1999.

A partir dessa variedade de edições e adaptações de Pinóquio, bem como seus elementos paratextuais, percebeu-se que seu público é bastante amplo e, portanto, este texto termina concordando com Ivo Barroso, tradutor da edição lançada pela Cosac Naify, quando diz que Pinóquio é um clássico para qualquer idade.

\section{Referências}

ACERVO Folha. http://acervo.folha.com.br/?cmpid=menulate> Acesso em: outubro de 2015.

ARAUJO, Rodrigo da Costa. De textos e de paratextos. Revista Palimpsesto, Rio de Janeiro, v. 10, ano 9, p.1-5, 2010. http://www.pgletras.uerj.br/palimpsesto/\&gws_rd=cr\&ei=mFA4Vui8EYqawgTfg7ywCg. Acesso em: out. 2015.

CALVINO, Ítalo. Posfácio. In: As aventuras de Pinóquio: Aventuras de um boneco. Tradução de Ivo Barroso. São Paulo: Cosac Naify, 2011. (Edição especial).

COLLODI, Carlo. Pinocchio: Aventuras maravilhosas de um boneco de pau. Tradução de Mary Bexter Lee. São Paulo: Livraria Liberdade, 1929.

Pinocchio. Tradução revista por Monteiro Lobato. São Paulo: Companhia Editora Nacional, 1933. (Série Literatura Infantil).

Pinocchio: as mais famosas aventuras fantásticas, jocosas e morais que empolgaram milhões de meninos e adultos do mundo inteiro, no livro e no cinema. Tradução direta de Mário da Silva. Rio de Janeiro: Casa Editora Vecchi Ltda, 1954. (Obras-primas Juvenis).

Pinocchio. Tradução revista por Monteiro Lobato. São Paulo: Companhia Editora Nacional, 1933.

As aventuras de Pinóquio: história de uma marionete. Tradução de Marina Colasanti. São Paulo: Companhia das Letrinhas, 2002.

As aventuras de Pinóquio: Aventuras de um boneco. Tradução de Ivo Barroso. São Paulo:

Cosac Naify, 2011.

As aventuras de Pinóquio: Aventuras de um boneco. Tradução de Ivo Barroso. São Paulo:

Cosac Naify, 2011. (Edição especial). 
GENETTE, Gérard. Paratextos Editoriais. Tradução de Álvaro Faleiros. São Paulo: Ateliê Editorial, 2009, 376 p.

PETERLE, Patricia (Org.). A literatura italiana traduzida no Brasil e a literatura brasileira traduzida na Itália: sob o olhar da tradução. Tubarão: Copiart, 2011.

PETERLE, Patricia, SANTURBANO, Andrea, WATAGHIN, Lucia (org.). Literatura italiana traduzida no Brasil 1900-1950. Niterói, RJ : Comunità, 2013

PEAD: Pedagogia - modalidade a distancia. Universidade Federal do Rio Grande do Sul. Rio Grande do Sul, 2010. http://pead.faced.ufrgs.br/sites/publico/ Acesso em: outubro 2015

Recebido em 22/12/2016

Aprovado em 20/05/2017 